\title{
Is planned adaptation to heat reducing heat-related mortality and illness? A systematic review
}

\author{
Melanie Boeckmann ${ }^{1,2^{*}}$ and Ines Rohn ${ }^{3}$
}

\begin{abstract}
Background: Extreme heat is an important public health risk. Climate change will likely increase the temperatures humans are exposed to through exacerbated heat wave intensity and frequency, possibly increasing health risks from heat. To prevent adverse effects on human health, heat prevention plans and climate change adaptation strategies are being implemented. But are these measures effectively reducing heat-related mortality and morbidity? This study assesses the evidence base in 2014.

Methods: We conducted a systematic review of peer-reviewed published literature. We applied a combined search strategy of automated search and journal content search using the electronic databases PubMed, Web of Knowledge, Biological Abstracts, CAB Abstracts and ProQuest Dissertation \& Theses A\&l. Quality appraisal was conducted using CASP checklists, and we identified recurrent themes in studies with content analysis methodology. We conducted sub-group analyses for two types of studies: survey and interview research on behavioral change and perception, and observational studies with regression.
\end{abstract}

Results: 30 articles were included in the review. The majority of studies $(n=17)$ assessed mortality or morbidity reductions with regression analysis. Overall, the assessments report a reduction of adverse effects during extreme heat in places where preventive measures have been implemented. Population perception and behavior change were assessed in five studies, none of which had carried out a pre-test. Two themes emerged from the review: methodological challenges are a major hindrance to rigorous evaluation, and what counts as proof of an effective reduction in adverse health outcomes is disputed.

Conclusions: Attributing health outcomes to heat adaptation remains a challenge. Recent study designs are less rigorous due to difficulties assigning the counterfactual. While sensitivity to heat is decreasing, the examined studies provide inconclusive evidence on individual planned adaptation measures.

Keywords: Heat, Climate change, Effectiveness, Systematic review, Cardiovascular disease, Respiratory disease

\section{Background}

Extreme heat is a public health risk [1-3]. In 2013, 58.729 heat stroke diagnoses have been recorded for Japan [4], for example, and the United States Centers for Disease Control report an annual 659 cases (on average) of heat-related deaths between 1999 and 2009 [5]. These numbers are likely underestimated: as the physical

\footnotetext{
* Correspondence: melanie.boeckmann@bips.uni-bremen.de

'Department Prevention and Evaluation, Leibniz Institute for Prevention

Research and Epidemiology - BIPS, Achterstr. 30, 28359, Bremen, Germany

${ }^{2}$ Center for Social Policy Research, University of Bremen, Mary-Somerville-Str.

5, 28359 Bremen, Germany

Full list of author information is available at the end of the article
}

effects of heat primarily exacerbate underlying conditions, diagnoses of death as heat-related are of varied quality [6]. Data availability on heat stroke incidence also depends on whether an emergency room or ambulance call occurs, as well as on active collection of such data. Heat increases the risk of dying of preexisting cardiovascular disease [6]; and heat stroke may lead to multiple organ failure [6-8]. Heat-related morbidity and mortality are preventable. Older persons, people taking medications that impair thermoregulation [6], very young children, socially isolated elderly, and people physically active outdoors during very hot periods have 
been identified as particularly at risk [9-12]. It has been argued that populations residing in urban centers are more vulnerable to heat events due to the urban heat island effect and higher population density [13-17]. In recent years additional concerns have arisen about a contribution of global warming to an increased frequency of extreme temperature events $[18,19]$. "Business as usual" climate change scenarios estimate that the incidence of heat events is likely to increase in the near future $[20,21]$. As a result, it has been suggested that future health risks from heat might increase [22-24]. In 2012, extreme temperature events classified as disasters by the WHO Collaborating Centre for Research on the Epidemiology of Disasters - CRED occurred 51 times worldwide, giving climatological disasters (temperature events, droughts and wildfires) an overall share of $23.8 \%$ of all 2012 disasters [25]. Recent severe heat waves occurred in Europe and Russia in 2003, 2006 and 2010, in the United States in 2012, in Australia in 2009 and 2013, and in Japan in 2010 and 2013, among others [26,27]. Beyond these extreme cases, smaller scale heat waves occur frequently and pose risks to human health. Heat impacts on humans can be measured through thermal indices [28]. Various methods to calculate a heat index exist, and without adherence to a standard, comparability between measurements and studies is challenging [29,30].

With a changing climate, populations of large cities in temperate regions, subtropical or tropical climates have all been characterized as vulnerable to heat $[3,31,32]$. Further measures may be needed to continually protect human health from adverse effects of heat on all continents. Adaptation to climate change has been defined as a "process of adjustment to actual or expected climate and its effects, in order to moderate harm or exploit beneficial opportunities" [33]. In this study, we are particularly interested in intentional, planned adaptation.

While we have conflicting information on risk perception of heat among populations $[11,34,35]$, older persons have been characterized as especially susceptible to ill effects of heat [36-38]. Heat warning systems have been introduced as a prevention measure [39-41]. These usually combine information from weather stations based on a cutoff system with more or less targeted communication campaigns. Such heat warning systems can now be found across the planet, usually at city level [42].

Despite increased interest in climate change and its impacts, and a large number of heat prevention plans in place in higher-income countries to protect human health $[39,43]$, we have hardly any conclusive evidence on the effects of said adaptation measures [44]. Is climate change adaptation to heat reducing heat stroke incidence and heat-related mortality? This study uses a systematic review design in an attempt to answer this question.

\section{Methods}

We conducted a systematic literature review of peerreviewed published literature. The PRISMA checklist, research protocol and the data extraction sheet can be found in the supplementary material (Additional files 1, 2 and 3). The scope of our review was as follows:

Population: urban populations of all ages, sexes and ethnic groups.

Intervention: Heat adaptation measures conducted in an urban area.

Because heat adaptation aims at preventing adverse health effects, we use the terms heat adaptation and heat prevention interchangeably in this review.

Comparison: none (no adaptation).

Outcomes: impacts on heat-related morbidity and mortality.

Context: International large urban centers ${ }^{\mathrm{a}}$.

The following outcomes were of interest:

- Impacts measured as reduction in excess heat stroke incidence, hospitalization for heat-related illness, and cases of cardiovascular, respiratory and all-cause mortality in extreme heat periods as compared to previous heat periods.

- Effectiveness measured

1) as reduction in excess heat stroke incidence, hospitalization for heat-related illness and cases of cardiovascular, respiratory and all-cause mortality, for which we accepted the proxy indicator of health services use (emergency medical care at facility or on ambulance; hospital release diagnosis or physician's diagnosis) for heat stroke,

2) as heat island exposure reduction signaled through changes in urban planning or taking up of heat warning systems.

\section{Search strategy}

We applied a combined search strategy of automated search and hand search of journals. Two researchers independently searched the electronic databases PubMed, Web of Knowledge, Biological Abstracts, CAB Abstracts and ProQuest Dissertation \& Theses A\&I.

We applied combinations of the search terms climat*, heat, adapt*, compounds of climate change, adaptation, adapting, heat wave, extreme heat, heat island combined with evaluat*, effect* and exposure in the automated searches ${ }^{\mathrm{b}}$.

Search strings had been pre-tested during a mapping review.

Additionally, both researchers manually searched the journals Climatic Change and International Journal of Climate Change Strategies and Management to increase our chances of finding articles that focus on evaluating 
adaptation strategies from a management or urban planning perspective.

Ancillary search procedures included checking the reference lists of identified primary studies as well as asking three leading international researchers for suggestions and works in progress.

\section{Selection criteria}

The following inclusion and exclusion criteria were applied:

\section{Inclusion}

Must include adaptation specifically for heat. All languages as long as an English abstract is available. Only reviews and original research articles as well as books or published national and international reports (defined as having an ISBN number). Must include at least one human health outcome, or health-related behavior changes. Must contain an evaluation or assessment. All publication years included.

\section{Exclusion}

No English abstract available. Comments, editorials, correspondences and letters are excluded. Mitigation rather than adaptation focus of the article. Focus too limited: only a description of heat adaptation planned or implemented without assessment of effects. No evaluation of human health impacts.

Two researchers independently selected relevant articles from the searches with the same search terms as well as through cross-checking reference lists. One researcher contacted leading experts for input on work-in-progress and further studies to be included via email.

Any disagreement between the two researchers was resolved and evaluated by a third member of the research team.

\section{Study quality assessment}

For study quality assessment, the NHS Critical Appraisal Skills Program (CASP) [45] checklists were used according to each study type. CASP also provides a checklist for quality appraisal of qualitative studies. Although specific tools for each study type prohibit a general comparison across study types, Katrak et al. [46] have previously criticized generic assessment tools for being too general. In addition, our review aimed at being comprehensive and therefore intentionally included a vast range of studies. Any attempt to assess these with a generic tool was unfit for representing their diversity. The CASP checklists were aimed at answering general guiding questions also provided by Booth et al. [47]:

1. Validity: Do the results of a study fit with other available evidence? How are confounding and bias handled?
2. Reliability: What are the results and how much might they be owed to chance?

3. Applicability: Can we generalize the results? How strong are recommendations for practice based on these study results?

For the specific questions, see Additional file 4.

To reduce the risk of subjective quality judgment, we decided not to exclude nor weigh studies based on quality rating or scales. While study quality assessment is important to judge the overall evidence base for adaptation effectiveness, the usefulness of excluding studies based on quality has been contested $[47,48]$.

\section{Study synthesis}

Due to the heterogeneity and varied designs of studies and reports, no overall quantitative meta-analysis could be performed. Instead, we applied narrative synthesis.

We conducted two subgroup analyses of survey studies and observational studies as these were the two most common study types.

\section{Results}

The database search led to 5539 results, 2299 after removal of duplicates. After title and abstract screening 2252 articles were excluded because they did not concern human health or did not contain an evaluation. 47 articles were assessed as full texts. We excluded 29 articles after reading the full texts because no evaluation according to our criteria was described. Through additional sources such as reference lists we identified 12 studies. All in all, 30 articles were included in the review, as shown in the PRISMA flowchart (Figure 1).

\section{Study characteristics}

Of the 30 articles, 12 were studies conducted in European countries [35,49-59], 10 studies were from the United States, one of which included a Canadian study city [34,60-68], two from East Asian countries $[69,70]$, one from Canada [71], and one from Australia [72]. The systematic reviews were not restricted to any continent [73-76]. Figure 2 shows the imbalance of country of origin for the publications in a distorted cartogram [77]: more studies were published in higherincome, Western countries versus lower-income countries. Countries with a higher output are represented as larger in the cartogram (Figure 2). We did not identify any studies from Africa, Southeast Asia or Central and South America. The Pacific Region was also underrepresented.

Time of publication ranged from 1992 to 2013 ( median $=2008)$. Regarding study population, about one-third of the studies focused on older persons $(\mathrm{n}=11)$ $[35,49,50,52,57-59,61,66,67,69]$. However, definitions of an 


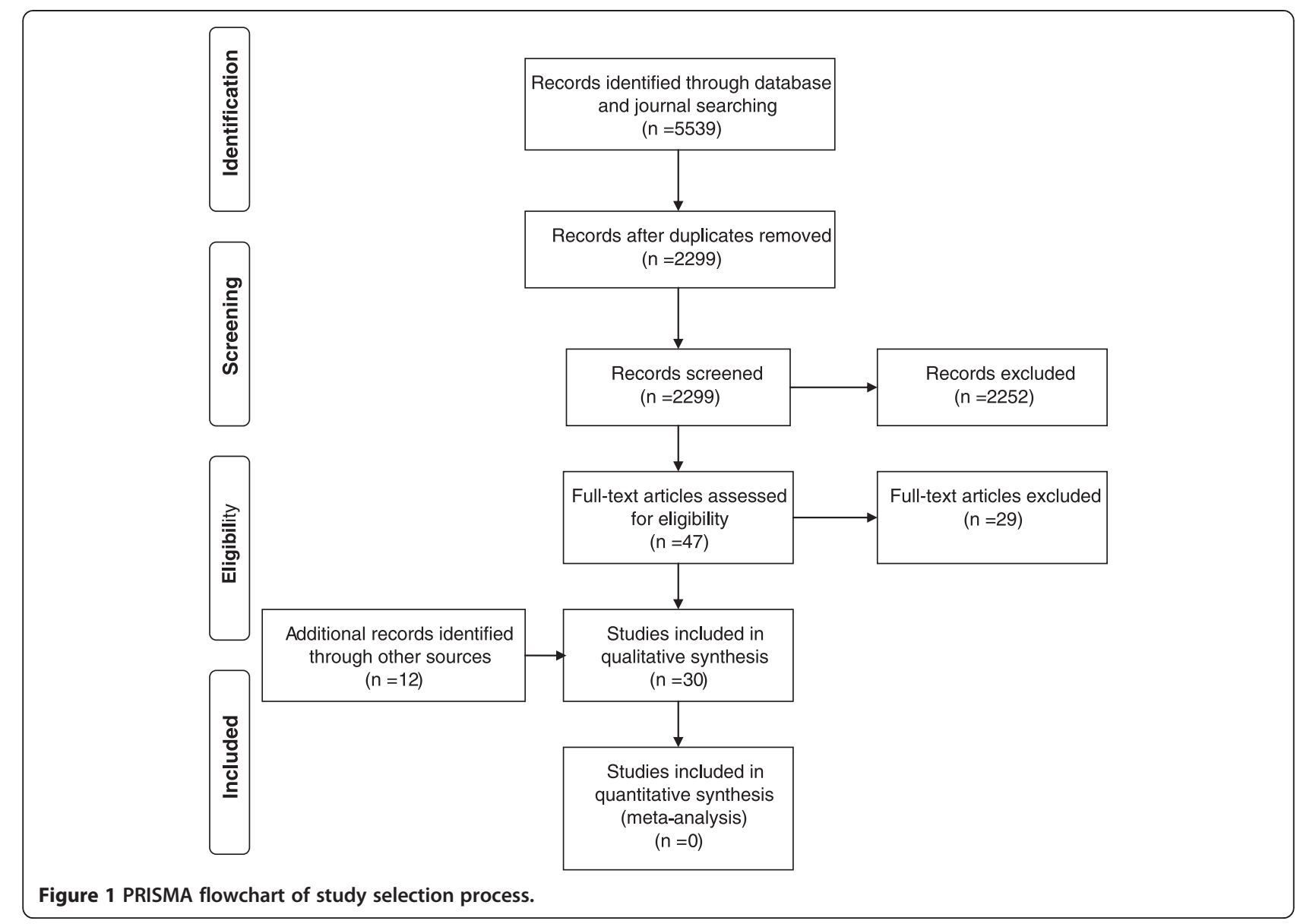

older person differed and ranged from inclusion of over 64 to 75 and beyond. The remaining studies included all adults aged 18 years and older.

Half of the identified studies were observational studies with regression as main analysis method $(\mathrm{n}=16)$ [49,51-53,55,56,58-60,63-65,67-70], followed by survey research $(n=6)[34,54,62,66,71,72]$. We identified two qualitative interview studies [35,50], one randomized controlled trial (RCT) [57], one economic analysis [61], and four systematic reviews [73-76]. Additional file 5 describes characteristics of the studies included in the review.

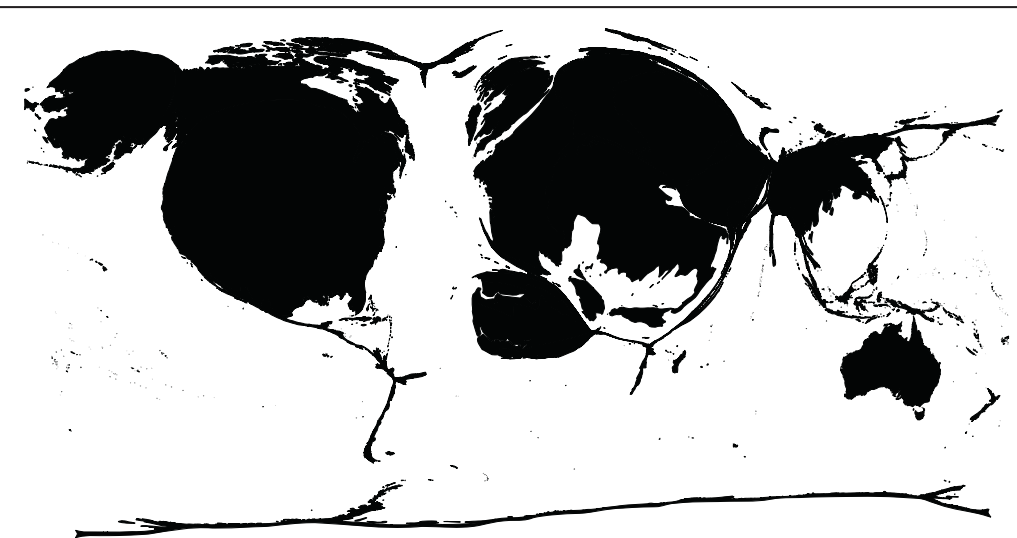

Figure 2 Continents of study origin. Distorted cartogram of continents of study origin, weighted by number of studies per country. Countries with higher number of publications are larger in the cartogram. 


\section{Heat adaptation}

Adaptation options to heat assessed in the included studies ranged from heat warning campaign communication [35,49,50], use of fans [75], and active surveillance programs [57] to biological acclimatization over decades $[55,56]$ (Figure 3).

Main outcomes were mortality rate trends over several years, mortality rates pre- and post-intervention, and changes in awareness or behavior over time. Due to limited comparability of the studies, specific study results will be discussed under subgroup analysis for regression analysis and perception survey results (Tables 1 and 2).

\section{Quality appraisal}

We used the CASP checklists [45] to assess study quality. As expected from scoping literature searches, studies included in the review were highly heterogeneous in research question and design. We used the CASP checklists for RCT $(n=1)$ [57], systematic reviews $(\mathrm{n}=4)$ [73-76], qualitative studies, also used for survey research $(n=7) \quad[34,35,50,54,66,71,72]$, case-control studies including one survey-based case-control study $(\mathrm{n}=15)$ [51-53,55,58-60,62-64,67-70,78], economic analyses $(n=1)$ [61] and cohort studies $(n=2)[49,65]$. Results of the quality appraisal are presented in Additional file 4 . Although we did not assign a quality score, we were able to see two main challenges for research design in the studies that may compromise quality: for survey and qualitative research on awareness changes, no baseline assessment was performed. For regression analyses, the definition of a control was not standardized.

\section{Subgroup analysis: articles comparing mortality and morbidity}

The majority of articles $(n=17)$ compared mortality or morbidity, either over a period of several years or before and after implementation of a heat wave warning system. Study types in this assessment included one RCT [57], 14 case-control studies [51-53,55,58,59,63,64,67-70,78,79] and 2 cohort studies $[49,65]$. However, the variety of outcomes reported prevented us from combining results in a meta-analysis (Figure 4).

Outcomes were reported as odds ratios, mortality rates, excess deaths, relative risk, increased percentage of mortality per centigrade temperature increase, or as a mortality index. Table 1 shows results of these studies. The studies were of high quality using standard epidemiological methods. Overall, the majority of assessments report a reduction of adverse effects during extreme heat. This applies both to longitudinal and short-term studies. For instance, Chau et al. [69] report an increase of 1.23 deaths from ischemic heart disease in Hong Kong where a heat warning system was absent between 1997 and 2005. For the cities in the United States, on the other hand, Davis et al. [60] find an increased heat-related mortality rate since 1964 for Atlanta, Buffalo, Dallas, Denver, Seattle and San Francisco. In Central Europe, Kysely and Plavcova [78] describe an overall decrease in mortality by $10 \%$ from 1986 to 2009 . A common challenge for the studies is linking the decrease to specific adaptation measures: alternative hypotheses for the observed declines in sensitivity have not been tested.

Subgroup analysis: perception and behavior change studies The second largest group of study types was comprised of awareness and perception surveys and interviews. The

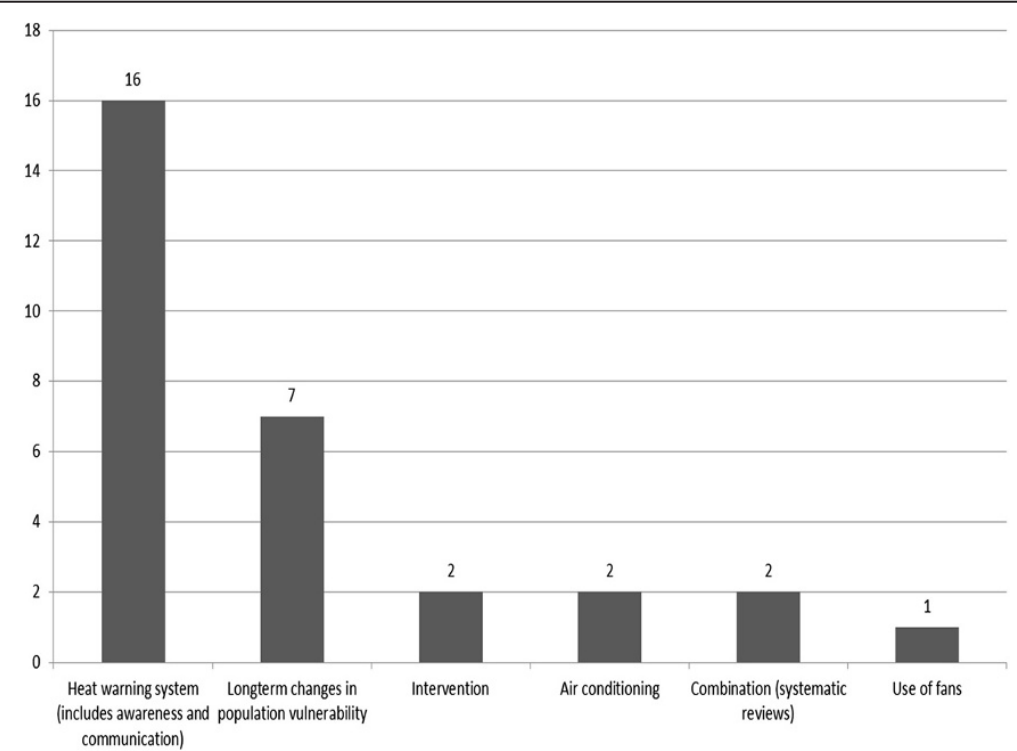

Figure 3 Type of adaptation in studies included in review. Adaptation measures discussed in the individual studies 
Table 1 Results of the regression analysis studies and RCT

\begin{tabular}{ll}
\hline Reference & Type of evaluation \\
\hline Rogot et al. 1992 [65] & $\begin{array}{l}\text { Comparing mortality during heat in people with air } \\
\text { conditioned homes to those with no air conditioning }\end{array}$
\end{tabular}

Smoyer 1998 [67] Comparing mortality rates of 1980 and 1995

Palecki et al. 2001 [64] Comparing excess deaths in 1995 and 1999

Weisskopf et al. Changes in population vulnerability

2002 [68]

Davis et al. 2003 [60] Comparing temperature mortality relationship from 1964 to 1998

Delaroziere and

Sanmarco 2004 [52]

Marinacci et al. 2009 [57]

Tan et al. 2007 [70] of warning system

Comparing no. of hospitalizations and deaths in summer 2004, RCT

Comparing daily excess mortality in 1998 and 2003.

De'Donato et al.

2008 [51]

Fouillet et al.

2008 [53]

Kysely and Kriz

2008 [55]

Bargagli et al.

2009 [49]

Chau et al. 2009 [69]

Ostro et al. 2010 [63]

Kysely and Plavcova 2012 [78]

Daily excess mortality before (reference period) and after implementation of heat warning system

Comparing excess daily mortality in 2003 to 2006

Comparing excess mortality in the 1990s and 2003 and those without = comparison of mortality rate with and without intervention
Comparing mortality before and after implementation

\section{Results}

Central air condition compared to no air condition: OR below

1 for all groups, significant ( $p=0.03$ Mantel-Haenszel). Room air condition compared to no air condition: OR 0.96 for total group, $p=0.71$ ). RR for central air condition vs. no air condition $\mathbf{0 . 5 8}$ for total group, RR for room air condition to no air condition 0.41 for total group

The average elderly mortality rate on heat wave days went down from 2.36 (SD 1.20) to 1.65 (SD 0.52), the average elderly mortality rate on non- heat days went down from 1.56 (SD 0.45) to 1.46 (SD 0.55)

Mortality rates in Chicago and St Louis both $\mathbf{1 . 4}$ per $\mathbf{1 0 0 . 0 0 0}$ in 1999, if not using core cities but counties. In 1995, 700 died in Chicago and 27 in St Louis

Model 1: predicted mortality rate of 1.80 per heat-index degree above $80^{\circ} \mathrm{F} .42 .3$ expected deaths, actual deaths in 1999 were 10. Model 2: RR for heat-related death in 1999: 0.17-0.24, RR for emergency medical services in 1999 0.32-0.46

The threshold for 1960s-1970s is no longer connected to an increased mortality in the 1980s in Northeastern cities, and in the 1990s 10 show no elevated mortality above threshold and of the remaining 18 cities 12 show a decline in mortality rate. Six cities remain with an increased mortality rate above the threshold: Atlanta, Buffalo, Dallas, Denver, Seattle, San Francisco

Mean index of daily excess mortality has dropped from 3.27 in the years 1986 to 1982 , down to $\mathbf{1 . 3 2}$ in the years 1984-1997, $p=0.008)$

Males: in intervention group Odds to be emergency hospitalized: OR $\mathbf{0 . 3 3}, \mathbf{9 5 \%} \mathrm{Cl}: \mathbf{0 . 1 1}$; 0.96. Females: in intervention group odds to be hospitalized overall: OR $0.96,95 \% \mathrm{Cl}$ : 0.93; 0.98

Correlation coefficient between daily deaths and weather and air pollution parameters: death and time of heat wave: $\mathbf{0 . 3 4}$ in 1998 and $\mathbf{0 . 4 1}$ in 2003, Tmax in 19980.51 to 0.62 in 2003. Heat related deaths in 1998: 358 (absolutes), 253 in 2003 (absolutes)

J-shape temperature-mortality curve in all cities. In Milan and Rome in 2007 there was a weaker association between high temps and mortality. In Bari and Catania there was a greater impact of high temp on mortality in 2007 (all compared to 2003). In 2007 excess mortality occurred during three heat waves, with impacts on mortality of $+10-41 \%$ in the center and $11-56 \%$ in the South

During summers 2004 and 2005, observed no. of deaths was 2-8\% lower than predicted no. of deaths. In 20062065 excess deaths occurred, predicted for that temperature were 6452 excess deaths, $\mathbf{4 4 0 0}$ fewer deaths than predicted

Excess daily mortality in 1990s: 98 deaths in 1992, 113 deaths in 1994; 50 deaths in 2003. Aggregated: 1992718 excess deaths, in 1994919 excess deaths, in 2003236 excess deaths

Excess mortality on heat days vs. non-heat days in controls: RR 1.20, 95\% Cl: 1.14-1.27; excess mortality on heat days vs. non-heat days in intervention patients: RR 0.95, 95\% Cl: 0.65-1.34

Absence of warning system was associated with an increase of $\mathbf{1 . 2 3}$ deaths from $\mathrm{HHD}(95 \% \mathrm{Cl} 0.32 ; 2.14)$, an increase of $\mathbf{0 . 9 7}$ deaths from stroke $(95 \% \mathrm{Cl}: 0.02 ; 1.92)$ per day

Reduction in excess risk of hospitalization with 10\% increase in A/C ownership: respiratory disease: relative reduction $19.9 \%(95 \% \mathrm{Cl}$ 0.7;39.), CVD relative reduction: $49.1 \%(95 \% \mathrm{Cl} 19.9 ; 78.3)$, heat stroke relative reduction $4.0 \%(95 \% \mathrm{Cl} 1.9 ; 6.0)$

Significant trends in deviation of mortality on lag days from 1986 to 2009: all ages $D+1-0.61, D+2-0.55 ; 70$ - years: $\mathrm{D}+1-0.66 ; 70+$ years: $\mathrm{D}+2-0.66$. Relative deviations of mortality 


\section{Table 1 Results of the regression analysis studies and RCT (Continued)}

\begin{tabular}{|c|c|c|}
\hline & & $\begin{array}{l}\text { declined by } 0.4 \% \text { to } 0.5 \% \text { in all age groups until } 2009 \text {. Overall } \\
\text { decline of mortality by } \mathbf{1 0} \% \text { for all groups }\end{array}$ \\
\hline $\begin{array}{l}\text { Morabito et al. } \\
2012[58]\end{array}$ & $\begin{array}{l}\text { Comparing mortality before and after implementation } \\
\text { of warning system }\end{array}$ & $\begin{array}{l}\text { Odds Ratios for mortality by age group pre- and post-2003: only } \\
\text { significant in } 75 \text { years+, OR for average apparent temperature } \\
\text { before } 2003 \mathbf{1 . 1 8} \text { (Cl } \mathbf{1 . 1 0 - 1 . 2 6 ) , ~} 2004 \text { to 2005: } \mathbf{1 . 2 4} \text { (Cl } \mathbf{1 . 1 4 - 1 . 3 5 ) ,} \\
\text { 2006-2007: } \mathbf{1 . 2 0} \text { (Cl } \mathbf{1 . 0 9 - 1 . 3 1 ) . ~ A l s o ~ s i g n i f i c a n t ~ f o r ~ m a x i m u m ~} \\
\text { temperature }\end{array}$ \\
\hline $\begin{array}{l}\text { Schifano et al. } \\
2012[59]\end{array}$ & $\begin{array}{l}\text { Comparing daily mortality in 1998-2002 (before) and } \\
\text { from } 2006 \text { to } 2010 \text { (after) implementation of } \\
\text { prevention program }\end{array}$ & $\begin{array}{l}\text { Weaker relationships between heat and mortality in all } \mathbf{1 6} \\
\text { cities post-intervention. Percentage change in mortality per } 3^{\circ} \mathrm{C} \\
\text { increase in max apparent temperature MAT (pooled results): for } \\
0 \text { to } 3 \% \text { increase of } 3^{\circ} \mathrm{C} \text { increase: } 1998-2002: 5.65 \% \text {, for } 2006 \text { to } \\
2010: 5.65 \% ; 3 \text { to } 6 \% \text { MAT increase: in 1998-2002 6.72\% change, } \\
\text { in } 2006 \text { to } 2010: 7.79 \% \text { change. Largest results: } \mathbf{1 2} \text { to } \mathbf{1 5 \%} \text { MAT } \\
\text { increase, } \mathbf{4 1 . 7 6 \%} \text { change from } \mathbf{1 9 9 8 - 2 0 0 2 ;} \mathbf{5 . 6 5 \%} \text { change from } \\
\mathbf{2 0 0 6} \text { to } \mathbf{2 0 1 0}\end{array}$ \\
\hline
\end{tabular}

Main results are in bold.

articles all shared a common definition of awareness and behavior change. No pre-test was conducted in the survey and interview studies except for the study by Mattern et al. [62]. Results are presented in Table 2.

Most participants were informed of risks of extreme heat through media, television being the most common $[34,54,66,71,72]$. Individual adaptation behaviors were use of air condition, drinking water and avoiding strenuous activities [34,35,50,54,66,71,72]. Risk perception was discussed in the publications by Abrahamson et al. [35] and Bittner and Stößel [50]: both discovered that among their participants, older persons did not feel more at risk than younger populations. Concern about the costs of increased air condition use was mentioned by Sheridan [66]. We argue that due to the lack of pretests, the success of behavioral intervention advice cannot be estimated conclusively as it cannot be compared to knowledge and behavioral habits prior to the implementation of an adaptation measure.

\section{Discussion}

The results of our review reveal difficulties in assessing adaptation effectiveness and are consistent with previous research. This suggests that issues of methodological rigor and what to measure when speaking about effectiveness of heat adaptation have not yet been resolved, despite increased interest in the matter.

Common themes in all studies were difficulties assessing adaptation effectiveness with standard epidemiological methods. This has been discussed particularly in the four systematic reviews. Specifically, the following issues in conducting rigorous studies to generate conclusive evidence of adaptation effects have been named:

- Differing heat wave impacts due to unstable intensity and frequency [76].

- Role of confounders such as socio-economic variables and long-term healthcare improvements [76].
- Short time frame between implementation of heat prevention and evaluation [73].

- Location-specific acclimatization [73].

- Simultaneous implementation of sub-interventions in a heat prevention plan [73].

- Data availability [76].

Gupta et al. [75] call for experimental study designs to assess the effectiveness of using fans during a heat wave as they were unable to resolve conflicting information from observational studies in their Cochrane review. In our included studies a call for more rigorous methods was the standard solution to the above mentioned issues, without specific recommendations on how to achieve this. When trying to judge whether the information we gathered through the review is sufficient proof that heat adaptation reduces heat-related mortality and illness, we struggle with the following problems posed by the available studies:

- Although older persons are generally included as a vulnerable group, age ranges differ and impede comparability.

- Lack of pre-tests in awareness studies. Participants' knowledge of heat warning systems or healthy behaviors cannot clearly be attributed to the adaptation.

- Most of the observational studies did not examine alternative hypotheses for changes. Often authors mentioned a variety of reasons for changes, all of them with equal or unknown likeliness.

Why is conducting experimental research of adaptation to heat so difficult? For one, defining the counterfactual, i.e. what would have happened in the absence of the adaptation measure, is problematic, because usually an entire city or even country is exposed to the adaptation measure. Choosing a different city as control would 
Table 2 Results of reviews, survey studies qualitative interview studies and economic analysis

\begin{tabular}{lll}
\hline Reference & Type of evaluation & Methods \\
\hline $\begin{array}{l}\text { Mattern et al. } \\
2000[62]\end{array}$ & Case-only survey & Standardized questionnaire \\
& & \\
Ebi et al. 2004 [61] & $\begin{array}{l}\text { Economic cost-effectiveness } \\
\text { evaluation }\end{array}$ & $\begin{array}{l}\text { Multiple linear regression, } \\
\text { estimation of lives saved, }\end{array}$
\end{tabular}

\section{estimation of benefits}

Kishonti et al. $2006[54]$
Bouchama et al. 2007 [74]

Kalkstein and Sheridan 2007 [3

Sheridan 2007 [66] State of knowledge on heat, protective behavior, available cooling systems in the house

Abrahamson et al. State of knowledge on 2009 [35] heat-related health risks and protective behavior State of knowledge on heat,
the warning system, protective behavior
State of knowledge on heat, the warning system, protective behavior
Quantitative telephone survey

Systematic review and meta-analysis

Quantitative survey

Quantitative telephone survey

Semi-structured interviews with topic guide, 1 data collection wave summer of 2007

\section{Results}

34 respondents. At pretest $67 \%$ of respondents knew whom to contact during heat for assistance, post-intervention $94 \%$ knew whom to contact. $6 \%$ knew about the City of Philadelphia hotline at pretest, $29 \%$ at post-test. $\mathbf{7 6} \%$ monitored temperature daily, $21 \%$ monitored temperature during hot days

2.6 lives saved on average for each warning day plus three day lag (not significant). Estimated value of $\$ 6.12 \mathrm{mill}$. per life $=\mathbf{\$ 4 6 8}$ mill. saved with $\mathbf{1 1 7}$ lives saved over $\mathbf{3}$ years. Costs for system $\$ 210.000$

Sample size 2500. Awareness of heat: persons between 30 and 59 years of age mentioned at least two health impacts of heat. $27 \%$ of respondents saw hypertension as risk, $11 \%$ heat stroke, 22\% CVD. 25\% of interviewees had seen the communication campaign, of whom $78 \%$ saw it on TV, $57 \%$ in the newspaper and $41 \%$ on the street. $\mathbf{5 9 \%}$ of respondents had heard of heat alarm

Protective factors: home air condition (OR 0.23 95\% Cl 0.1-0.6) visiting cool environments (OR $0.3495 \% \mathrm{Cl}$ 0.2-0.5), increased social contact (OR $0.4095 \% \mathrm{Cl} \mathbf{0 . 2}-\mathbf{0 . 8}$ ), taking extra showers (OR $\mathbf{0 . 3 2}, \mathbf{9 5 \%} \mathrm{Cl} \mathbf{0 1 . - 1 . 1}$ ), use of fans (OR 0.60 95\% CI 0.4-1.1)

201 respondents, 14 of age $65+.90 .2 \%$ of females knew about the heat warning system, $75.3 \%$ of males knew about the system. 25\% felt heat was dangerous. Of those aware of heat warnings, $\mathbf{4 9 . 7 \%}$ altered behavior, $47.3 \%$ did not

908 respondents across all cities. In the four cities, most people learned about heat warnings on television (Dayton: 89\%, Philadelphia: 84\%, Phoenix: 92\%, Toronto: 64\%). $\mathbf{4 6 \%}$ of respondents altered their behavior during heat, varying significantly across cities $(p=0.003)$. Use of air conditioning self-restricted due to concerns about costs

73 respondents, mean age 81 years (range 72-90) in London; mean age 80 (range 75 to 94) in Norwich. Themes identified: perception of vulnerability to heat; behavior change during heat; knowledge of protection measures; perception of usefulness of heat wave plan. No consensus on usefulness of heat wave plan components. Most respondents adjust their behavior during heat. Few respondents perceived of themselves at risk

Quantitative, questionnaire based 238 respondents. 86\% know about risks of high night time temperature, 94\% know about health risks for lung and
State of knowledge on heat, protective behavior face-to-face interviews

2010 [73]

Oakman et al 2010 [72]

Bittner and Stößel 2012 [50]

Gupta et al.

2012 [75]
Systematic review and expert elicitation

State of knowledge on heat, protective behavior, heat warnings

Systematic review of all study types

State of knowledge on heat, heat warnings, protective behavior

Quantitative telephone survey

Questionnaire-based interviews, qualitative analysis with framework approach

Systematic review according to Cochrane guidelines heart disease patients. $80 \%$ listen to weather forecasts, mid-summer $\mathbf{9 3 \%}$ had heard a heat advisory. $71 \%$ use a fan, $87 \%$ do less strenuous activities in heat. $73 \%$ have air condition at home, those with air condition reported more additional behavior changes than those without

Narrative results: most studies evaluate heat warning systems, awareness and perception. If effects measured then often as regression analysis. Methodological challenges

328 interviews, $\mathbf{6 3} \%$ knew of health warnings: of these $74 \%$ saw it on TV, $42 \%$ on radio, $15 \%$ in newspapers. $96.1 \%$ of respondents used air condition in hot weather, $94 \%$ drank water, $90 \%$ stayed indoors

20 respondents. Themes: vulnerability, changes in daily routine, sources of information, content of advice received, activity level and health status. Individual vulnerability not always perceived. Controversial role of the GP. 19 respondents stated they changed behavior with controls 


\section{Table 2 Results of reviews, survey studies qualitative interview studies and economic analysis (Continued)}

\begin{tabular}{|c|c|c|c|}
\hline $\begin{array}{l}\text { Toloo et al. } \\
2013[44]\end{array}$ & $\begin{array}{l}\text { Systematic review of any heat } \\
\text { warning evaluation }\end{array}$ & Systematic review of databases & $\begin{array}{l}\text { Six articles asserted that post-intervention expected deaths } \\
\text { were reduced. High study heterogeneity. One economic } \\
\text { assessment. Eight studies assessed awareness, including one } \\
\text { qualitative study }\end{array}$ \\
\hline
\end{tabular}

Main results are in bold.

require careful matching. This is difficult for many reasons: for example, intercity microclimate variability could bias results, and to assess effects the control city would need to be exposed to a heat event of similar magnitude and length. Unlike other public health interventions, researchers and practitioners cannot limit exposure; they can only mediate it.

Second, heat prevention can occur at structural level, or at individual level through behavior change. Ethical concerns could be raised if structural prevention or a warning system were only available to an intervention group in one city. For instance, control populations could not be prevented from accessing public green spaces.

Third, heat by itself is not a new phenomenon. Much of the heat-related health advice provided by risk communication campaigns is common sense information: to stay hydrated, for example, or to seek shade and cool places [80]. Physical discomfort during heat makes it likely that people have followed such advice before official warnings were even issued. This might not only suggest absence of the classic control group for behavior, it is also more difficult to compare knowledge pre- and post-information campaigns. In light of future population aging, potential improvements to adaptation effects lie with targeting those elderly people who do not feel at risk through awareness raising interventions despite these difficulties. The use of innovative materials and social norms approaches could be evaluated.

While we argue that concrete evidence for the effectiveness of specific planned adaptation measures is lacking, our results show a mostly unanimous decline in sensitivity to heat over longer time periods. Alternative hypotheses for the causes of this decline should be investigated. Proposed alternatives have included biological adaptation [81], improvements to healthcare systems [82], technological advancements [83], adjustments to the urban built environment [84], and social progress [84]. The role each of the alternatives plays in declining heat sensitivity is debated [78].

Aware of these shortcomings, recent research projects into methods specifically for adaptation assessments have been designed [85], results are not yet available.

We were surprised to be unable to identify articles assessing infrastructural measures such as greening, or supply of air conditioning, although we had specifically intended to include these. Our focus on human health and our health-related search terms may have prevented us from finding articles on urban planning effects. Connecting specific urban planning to public health assessments might be a challenging but interesting future research topic.

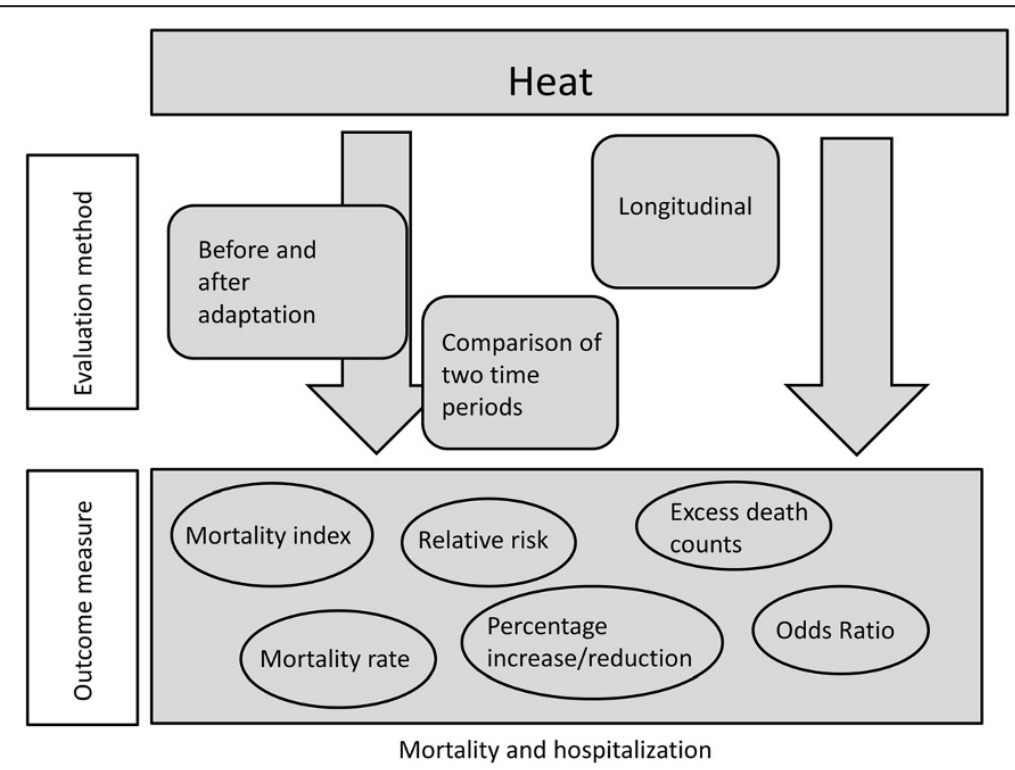

Figure 4 Model of the variability in reported outcomes. 


\section{Policy implications}

With such little conclusive evidence of effectiveness, recommendations for future action need to be carefully considered. On the one hand, policymakers may feel a moral imperative to act regardless of the evidence base. On the other hand, negative health effects of the adaptation measures themselves should be avoided. Possible risks from adaptation include misinformation on protective behaviors leading to maladaptation, or increased allergic disease incidence through greening of urban spaces [86]. Using "low-regret" adaptation measures could be an interim solution until more suitable assessment methods have been developed. In climate change adaptation, low-regret options are generally all strategies that either offer more than one benefit or keep options for amendments open $[87,88]$. Such options have been described as useful when uncertainties are large, as they do not rely on exact climate change projections $[88,89]$. They yield a number of benefits for a system's capacities to deal with climatic changes while only requiring moderate input, and are less likely to have negative effects $[87,88]$. In practice, benefits will have to be weighed against opportunity costs and trade-offs [90].

Examples for popular low-regret options in heat adaptation might be urban greening and heat wave warnings [91]. However, creating such an inventory of low-regret measures does not actually solve the issue of whether adaptation works. A prominent voice in climate change and health research, Anthony McMichael, argued that a focus on traditional epidemiological assessments methods may not lead to increased knowledge as desired [92]. Instead, McMichael wrote, taking risks with new concepts, methods and interdisciplinary approaches to research are required [92].

\section{Limitations}

In this review, we focused on peer-reviewed literature and excluded all unpublished or grey literature directing main attention towards database searches. This was justified by our specified interest in evidence of effectiveness as proven by rigorous scientific research, rather than in any evaluation possibly conducted by practitioners. A previous review from 2010 [73] stated that grey literature would be a more likely source of effectiveness information than peer-reviewed journal articles owing to the low number of evaluations conducted in research. Nonetheless, Bassil and Cole [73,93] only found one unpublished study that contributed to the information on effects. As there is no legal imperative for policymakers in Europe to evaluate adaptation strategies, for example, few assessments are undertaken [94]. We aimed for comprehensiveness and therefore included nonhealth related databases to search for infrastructural evaluations. The final article selection, however, was entirely from academic health and medicine journals. This suggests that even if evaluation of green spaces or other infrastructural measures occur, these evaluations are less likely to consider co-effects on human health.

We identified no articles from Africa, Southeast Asia, the Pacific or Central and South America. This confirms previous findings on a dominance of high-income Western countries in adaptation research [95].

Nevertheless, we were able to identify 30 articles dealing with issues of evaluating heat adaptation, a large number in light of the novelty of adaptation and evaluation research. By our subgroup analysis approach, we contributed to knowledge on effectiveness as generated by two current adaptation evaluation standards: awareness surveys and mortality rate comparisons. Our review identifies major challenges to evaluation and proposes further research into the potential of adaptation measures for health protection from extreme heat.

\section{Conclusions}

Our results show that rigorous evaluation of adaptation is rare and difficult to conduct. The potential health effects of adaptation can currently not be measured conclusively. Up to now, we find limited intersectoral efforts between public health agencies and climate change adaptation policy. Such efforts might contribute to a reduction in adverse health effects of heat. In addition, involvement of the health sector in adaptation design, implementation and evaluation might increase chances of successful adaptation.

Current knowledge does not prove effectiveness of planned adaptation, yet a decline in sensitivity to heat hints at important developments. Recent articles published after the search period for this review observe a similar decline over long time periods [96-98]. Whether biological adaptation, continuous improvements in healthcare, changes to the urban environment not declared "adaptation," or a different unknown reason caused said decline is a matter of further interest. The seeming paradox between the observed decline in the examined studies and scholarly works referring to an expected increase in heat-related adverse health effects [99] needs to be assessed further as well. Low-regret adaptation options might be investigated while simultaneously increasing efforts to overcome methodological evaluation challenges with further research.

\section{Endnotes}

${ }^{a}$ Originally we had planned to include only cities with more than 500,000 inhabitants. Due to the limited study availability, however, we decided to broaden this criterion to cities of any size.

$\mathrm{b}_{*}=$ wildcard, all possible word endings included. 


\section{Additional files}

\author{
Additional file 1: PRISMA checklist. \\ Additional file 2: Review protocol. The protocol for the systematic \\ review.
}

Additional file 3: Data extraction sheet.

Additional file 4: Quality appraisal results. The results of the quality appraisal conducted with CASP checklists.

Additional file 5: Table of characteristics of studies included in review. Studies are presented ordered by type and year of publication.

\section{Competing interests}

The authors declare that they have no competing interests.

\section{Authors' contributions}

MB conceptualized the study, conducted the literature search, study quality appraisal and data analysis, and wrote the article. IR conducted the literature search, study quality appraisal during the data extraction stage, and participated in writing the draft. Both authors read and approved the final version of this manuscript.

\section{Acknowledgements}

MB was supported by a Leibniz Institute for Prevention Research and Epidemiology - BIPS and University of Bremen joint dissertation scholarship. The authors thank Prof. Hajo Zeeb for support throughout the study and for helpful comments on the manuscript, as well as Berit Steenbock and Edda Hein for critical reading of the article drafts. MB would like to thank Michael Lehmann for an introduction to the program ScapeToad for cartograms. Both authors thank the three reviewers for their thoughtful comments that helped improve the manuscript.

\section{Author details}

${ }^{1}$ Department Prevention and Evaluation, Leibniz Institute for Prevention Research and Epidemiology - BIPS, Achterstr. 30, 28359, Bremen, Germany. ${ }^{2}$ Center for Social Policy Research, University of Bremen, Mary-Somerville-Str. 5, 28359 Bremen, Germany. ${ }^{3}$ Medical University Hannover, Carl-Neuberg-Str 1, 30625 Hannover, Germany.

Received: 2 May 2014 Accepted: 25 September 2014

Published: 28 October 2014

\section{References}

1. Baccini M, Kosatsky T, Analitis A, Anderson HR, D'Ovidio M, Menne B, Michelozzi P, Biggeri A, the PHEWE Collaborative Group: Impact of heat on mortality in 15 European cities: attributable deaths under different weather scenarios. J Epidemiol Community Health 2011, 65:64-70.

2. Ng CFS, Ueda K, Ono M, Nitta H, Takami A: Characterizing the effect of summer temperature on heatstroke-related emergency ambulance dispatches in the Kanto area of Japan. Int J Biometeorol 2014, 58:941-948.

3. McMichael AJ, Wilkinson P, Kovats RS, Pattenden S, Hajat S, Armstrong B, Vajanapoom N, Niciu EM, Mahomed H, Kingkeow C, Kosnik M, O'Neill MS, Romieu I, Ramirez-Aguilar M, Barreto ML, Gouveia N, Nikiforov B: International study of temperature, heat and urban mortality: the "ISOTHURM" project. Int J Epidemiol 2008, 37:1121-1131.

4. Heatstroke information. http://www.fdma.go.jp/neuter/topics/houdou/h25/ 2510/251015_1houdou/01_houdoushiryou.pdf

5. Fowler DR, Mitchell CS, Brown A, Pollock T, Bratka LA, Paulson J, Noller AC, Mauskapf R, Oscanyan K, Vaidyanathan A, Wolkin A, Taylor EV, Radcliffe R: Heat-related deaths after an extreme heat event - Four States, 2012, and United States, 1999-2009. Morb Mortal Wkly Rep 2013, 62:433-436.

6. Yeo TP: Heat stroke: a comprehensive review. AACN Clin Issues Adv Pract Acute Crit Care 2004, 15:280-293.

7. Bouchama A, Knochel JP: Heat stroke. N Engl J Med 2002, 346:1978-1988.

8. Atha WF: Heat-related illness. Emerg Med Clin North Am 2013, 31:1097-1108.

9. Martinez M, Devenport L, Saussy J, Martinez J: Drug-associated heat stroke. South Med J 2002, 95:799-802.

10. Green H, Gilbert J, James R, Byard RW: An analysis of factors contributing to a series of deaths caused by exposure to high environmental temperatures. Am J Forensic Med Pathol 2001, 22:196-199.
11. Wolf J, Adger WN, Lorenzoni I, Abrahamson V, Raine R: Social capital, individual responses to heat waves and climate change adaptation: an empirical study of two UK cities. Glob Environ Chang 2010, 20:44-52.

12. Kenny GP, Yardley J, Brown C, Sigal RJ, Jay O: Heat stress in older individuals and patients with common chronic diseases. CMAJ 2010, 182:1053-1060.

13. Rosenthal JK: Evaluating the Impact of the Urban Heat Island on Public Health: Spatial and Social Determinants of Heat-Related Mortality in New York City. New York City: Columbia University; 2010.

14. Laaidi K, Zeghnoun A, Dousset B, Bretin P, Vandentorren S, Giraudet E, Beaudeau P: The impact of heat islands on mortality in Paris during the August 2003 heat wave. Environ Health Perspect 2012, 120:254-259.

15. Tan J, Zheng Y, Tang X, Guo C, Li L, Song G, Zhen X, Yuan D, Kalkstein AJ, Li $F$ : The urban heat island and its impact on heat waves and human health in Shanghai. Int J Biometeorol 2010, 54:75-84.

16. Stone B, Hess JJ, Frumkin H: Urban form and extreme heat events: are sprawling cities more vulnerable to climate change than compact cities? Environ Health Perspect 2010, 118:1425-1428.

17. Oikonomou E, Davies M, Mavrogianni A, Biddulph P, Wilkinson P, Kolokotroni M: Modelling the relative importance of the urban heat island and the thermal quality of dwellings for overheating in London. Build Environ 2012, 57:223-238.

18. IPCC: Summary for Policymakers. In Clim Chang 2007 Impacts, Adapt Vulnerability Contrib Work Gr II to Fourth Assess Rep Intergov Panel Clim Chang. Edited by Parry ML, Canziani OF, Palutikof JP, van der Linden PJ, Hanson CE. Cambridge: Cambridge University Press; 2007:7-22.

19. IPCC: Summary for policymakers. In Clim Chang 2007 Phys Sci Basis Contrib Work Gr I to Fourth Assess Rep Intergov Panel Clim Chang. Edited by Solomon S, Qin D, Manning M, Chen Z, Marquis M, Averyt KB, Tignor M, Miller HL. Cambridge [u.a.]: Cambridge University Press; 2007:1-18.

20. Greene S, Kalkstein LS, Mills DM, Samenow J: An examination of climate change on extreme heat events and climate-mortality relationships in large U.S. cities. Weather Clim Soc 2011, 3:281-292.

21. Huang C, Barnett AG, Wang X, Vaneckova P, FitzGerald G, Tong S: Projecting future heat-related mortality under climate change scenarios: a systematic review. Environ Health Perspect 2011, 119:1681-1690.

22. Hajat S, Vardoulakis S, Heaviside C, Eggen B: Climate change effects on human health: projections of temperature-related mortality for the UK during the 2020s, 2050s and 2080s. J Epidemiol Community Heal 2014, 68(7):641-648.

23. Knowlton K, Lynn B, Goldberg RA, Rosenzweig C, Hogrefe C, Rosenthal JK, Kinney PL: Projecting heat-related mortality impacts under a changing climate in the New York City region. Am J Public Health 2007, 97:2028-2034.

24. Morabito M, Crisci A, Moriondo M, Profili F, Francesconi P, Trombi G, Bindi M, Gensini GF, Orlandini S: Air temperature-related human health outcomes: current impact and estimations of future risks in Central Italy. Sci Total Environ 2012, 441:28-40.

25. Guha-Sapir D, Hoyois P, Below R: Annual Disaster Statistical Review 2012: The Numbers and Trends. Brussels: Centre for Research on the Epidemiology of Disasters (CRED) and Institute of Health and Society (IRSS) Université catholique de Louvain; 2012.

26. Coumou D, Robinson A, Rahmstorf S: Global increase in record-breaking monthly-mean temperatures. Clim Change 2013, 118:771-782.

27. Coumou D, Robinson A: Historic and future increase in the global land area affected by monthly heat extremes. Environ Res Lett 2013, 8:034018

28. Black $\mathrm{H}$ : When to warn? comparing heat indices to evaluate public health risks. Environ Health Perspect 2010, 118:A35.

29. Anderson GB, Bell ML, Peng RD: Methods to calculate the heat index as an exposure metric in environmental health research. Environ Health Perspect 2013, 121:1111-1119.

30. Morabito M, Crisci A, Messeri A, Capecchi V, Modesti PA, Gensini GF, Orlandini S: Environmental temperature and thermal indices: what is the most effective predictor of heat-related mortality in different geographical contexts? Sci World J 2014, 2014:961750.

31. Handmer J, Honda Y, Kundzewicz ZW, Arnell N, Benito G, Hatfield J, Mohamed IF, Peduzzi P, Wu S, Sherstyukov B, Takahashi K, Yan Z: Changes in impacts of climate extremes: human systems and ecosystems. In Manag Risks Extrem Events Disasters to Adv Clim Chang Adapt A Spec Rep Work Groups I II Intergov Panel Clim Chang (IPCC). Edited by Field CB, Barros V, Stocker TF, Qin D, Dokken DJ, Ebi KL, Mastrandrea MD, Mach KJ, Plattner 
G-K, Allen SK, Tignor M, Midgley PM. Cambridge, New York: Cambridge University Press; 2012:231-290.

32. Patz JA, Campbell-Lendrum D, Holloway T, Foley JA: Impact of regional climate change on human health. Nature 2005, 438:310-317.

33. IPCC: Managing the Risks of Extreme Events and Disasters to Advance Climate Change Adaptation. A Special Report of Working Groups I and II of the Intergovernmental Panel on Climate Change. Cambridge and New York: Cambridge University Press; 2012:582

34. Kalkstein A, Sheridan S: The social impacts of the heat-health watch/ warning system in Phoenix, Arizona: assessing the perceived risk and response of the public. Int J Biometeorol 2007, 52:43-55.

35. Abrahamson V, Wolf J, Lorenzoni I, Fenn B, Kovats S, Wilkinson P, Adger WN Raine R: Perceptions of heatwave risks to health: interview-based study of older people in London and Norwich, UK. J Public Health (Oxf) 2009, 31:119-126.

36. Gronlund CJ, Zanobetti A, Schwartz JD, Wellenius GA, O'Neill MS: Heat, heat waves, and hospital admissions among the elderly in the United States, 1992-2006. Env Heal Perspect 2014. http://ehp.niehs.nih.gov/1206132/.

37. Schifano P, Cappai G, De SM, Bargagli AM, Michelozzi P: Who should heat prevention plans target? A heat susceptibility indicator in the elderly developed based on administrative data from a cohort study. Heal Aging Res 2013, 2: http://dx.doi.org/10.12715/har.2013.2.2.

38. Sampson NR, Gronlund CJ, Buxton MA, Catalano L, White-Newsome JL, Conlon KC, O'Neill MS, McCormick S, Parker EA: Staying cool in a changing climate: reaching vulnerable populations during heat events. Glob Environ Chang 2013, 23:475-484

39. Bittner M-I, Matthies EF, Dalbokova D, Menne B: Are European countries prepared for the next big heat-wave? Eur J Public Health 2013, 24(4):615-619.

40. Kovats RS, Kristie LE: Heatwaves and public health in Europe. Eur J Public Health 2006, 16:592-599.

41. Ebi KL, Burton I: Identifying practical adaptation options: an approach to address climate change-related health risks. Environ Sci Policy 2008, 11:359-369.

42. Lowe D, Ebi KL, Forsberg B: Heatwave early warning systems and adaptation advice to reduce human health consequences of heatwaves. Int J Environ Res Public Health 2011, 8:4623-4648.

43. Martinez GS, Imai C, Masumo K: Local heat stroke prevention plans in Japan: characteristics and elements for public health adaptation to climate change. Int J Environ Res Public Heal 2011, 8:4563-4581.

44. Toloo G, Fitzgerald G, Aitken P, Verrall K, Tong S: Evaluating the effectiveness of heat warning systems: systematic review of epidemiological evidence. Int J Public Health 2013, 58:667-681.

45. Critical appraisal skills programme: making sense of evidence. http://www.casp-uk.net.

46. Katrak P, Bialocerkowski AE, Massy-Westropp N, Kumar S, Grimmer KA: A systematic review of the content of critical appraisal tools. BMC Med Res Methodol 2004, 4:22.

47. Booth A, Papaioannou D, Sutton A: Systematic Approaches to a Successful Literature Review. Los Angeles [u.a.]: Sage; 2012.

48. Carroll C, Booth A, Lloyd-Jones M: Should we exclude inadequately reported studies from qualitative systematic reviews? An evaluation of sensitivity analyses in two case study reviews. Qual Health Res 2012, 22:1425-1434.

49. Bargagli AM, Michelozzi P, Marino C, De Sario M, Schifano P, Cappai G, Perucci CA: Heat health effect prevention: evaluation of the active surveillance program of high risk elderly in Rome, summer 2008. Epidemiology 2009, 20:S75-S75.

50. Bittner Ml, Stößel U: Perceptions of heatwave risks to health: results of an qualitative interview study with older people and their carers in Freiburg, Germany. Psychosoc Med 2012, 9:Doc05

51. de'Donato FK, Michelozzi P, Bargagli A, Di Gennaro M, D'Ippoliti D, Leonardi MJ Marino C, Schifimo P, Perucci C: The Italian heat/health warning system for prevention of heat health effects; evaluation of summer 2008. Epidemiology 2008, 19:S287-S288.

52. Delaroziere JC, Sanmarco JL: Excess mortality in people over 65 years old during summer heat waves in Marseille. comparison before and after a preventive campaign. Presse Med 2004, 33:13-16.

53. Fouillet A, Rey G, Wagner V, Laaidi K, Empereur-Bissonnet P, Le Tertre A, Frayssinet $P$, Bessemoulin $P$, Laurent $F$, De Crouy-Chanel $P$, Jougla $E$, Hémon $D$ : Has the impact of heat waves on mortality changed in France since the European heat wave of summer 2003? a study of the 2006 heat wave. Int J Epidemiol 2008, 37:309-317.

54. Kishonti K, Paldy A, Bobvos J: Evaluation of the communication of the heat-health-watch-warning system in Hungary. Epidemiology 2006 17:S427-S428

55. Kysely J, Kriz B: Decreased impacts of the 2003 heat waves on mortality in the Czech Republic: an improved response? Int J Biometeorol 2008, 52:733-745.

56. Kyselý J, Plavcová E: Declining impacts of hot spells on mortality in the Czech Republic, 1986-2009: adaptation to climate change? Clim Change 2011, 113:437-453.

57. Marinacci C, Marino M, Ferracin E, Fubini L, Gilardi L, Visentin P, Cadum E, Costa G: Testing of interventions for prevention of heat wave related deaths: results among frail elderly and methodological problems. Epidemiol Prev 2009, 33:96-103.

58. Morabito M, Profili F, Crisci A, Francesconi P, Gensini GF, Orlandini S: Heat-related mortality in the Florentine area (Italy) before and after the exceptional 2003 heat wave in Europe: an improved public health response? Int J Biometeorol 2012, 56:801-810.

59. Schifano P, Leone M, De Sario M, De'donato F, Bargagli AM, D'lppoliti D, Marino C, Michelozzi P: Changes in the effects of heat on mortality among the elderly from 1998-2010: results from a multicenter time series study in Italy. Environ Health 2012, 11:58.

60. Davis RE, Knappenberger PC, Michaels PJ, Novicoff WM: Changing heat-related mortality in the United States. Environ Health Perspect 2003, 111:1712-1718.

61. Ebi KL, Teisberg TJ, Kalkstein LS, Robinson L, Weiher RF: Heat watch/warning systems save lives - estimated costs and benefits for Philadelphia 1995-98. Bull Am Meteorol Soc 2004, 85:1067-1073.

62. Mattern J, Garrigan S, Kennedy SB: A community-based assessment of heat-related morbidity in North Philadelphia. Environ Res 2000, 83:338-342.

63. Ostro B, Rauch S, Green R, Malig B, Basu R: The effects of temperature and use of air conditioning on hospitalizations. Am J Epidemiol 2010, 172:1053-1061.

64. Palecki MA, Changnon SA, Kunkel KE: The nature and impacts of the July 1999 heat wave in the Midwestern United States: Learning from the lessons of 1995. Bull Am Meteorol Soc 2001, 82:1353-1367.

65. Rogot E, Sorlie PD, Backlund E: Air-conditioning and mortality in hot weather. Am J Epidemiol 1992, 136:106-116.

66. Sheridan S: A survey of public perception and response to heat warnings across four North American cities: an evaluation of municipal effectiveness. Int J Biometeorol 2007, 52:3-15.

67. Smoyer KE: A comparative analysis of heat waves and associated mortality in St. Louis, Missouri-1980 and 1995. Int J Biometeorol 1998, 42:44-50.

68. Weisskopf MG, Anderson HA, Foldy S, Hanrahan LP, Blair K, Torok TJ, Rumm PD: Heat wave morbidity and mortality, Milwaukee, Wis, 1999 vs 1995: an improved response? Am J Public Health 2002, 92:830-833.

69. Chau P, Chan K, Woo J: Hot weather warning might help to reduce elderly mortality in Hong Kong. Int J Biometeorol 2009, 53:461-468.

70. Tan J, Zheng Y, Song G, Kalkstein L, Kalkstein A, Tang X: Heat wave impacts on mortality in Shanghai, 1998 and 2003. Int J Biometeorol 2007, 51:193-200.

71. Kosatsky T, Dufresne J, Richard L, Renouf A, Giannetti N, Bourbeau J, Julien $M$, Braidy J, Sauve C: Heat awareness and response among Montreal residents with chronic cardiac and pulmonary disease. Can J Public Heal Can sante publique 2009, 100:237-240.

72. Oakman T, Byles-Drage H, Pope R, Pritchard J: Beat the Heat: don't forget your drink - a brief public education program. Aust N Z J Public Health 2010, 34:346-350.

73. Bassil KL, Cole DC: Effectiveness of public health interventions in reducing morbidity and mortality during heat episodes: a structured review. Int J Environ Res Public Health 2010, 7:991-1001.

74. Bouchama A, Dehbi M, Mohamed G, Matthies F, Shoukri M, Menne B: Prognostic factors in heat wave related deaths: a meta-analysis. Arch Intern Med 2007, 167:2170-2176.

75. Gupta S, Carmichael C, Simpson C, Clarke MJ, Allen C, Gao Y, Chan EYY, Murray $\vee$ : Electric fans for reducing adverse health impacts in heatwaves. Cochrane Database Syst Rev 2012, 7:1-24.

76. Toloo GS, Fitzgerald G, Aitken P, Verrall K, Tong S: Are heat warning systems effective? Environ Heal 2013, 12:27. 
77. Andrieu D, Kaiser C, Ourednik A: ScapeToad. 2008.

78. Kyselý J, Plavcová E: Declining impacts of hot spells on mortality in the Czech Republic, 1986-2009: adaptation to climate change? Clim Change 2012, 113:437-453.

79. Davis RE, Knappenberger PC, Novicoff WM, Michaels PJ: Decadal changes in summer mortality in U.S. cities. Int I Biometeorol 2003, 47:166-175.

80. Frumkin H, Hess J, Luber G, Malilay J, McGeehin M: Climate change: the public health response. Am J Public Health 2008, 98:435-445.

81. Ballester J, Robine J-M, Herrmann FR, Rodó X: Long-term projections and acclimatization scenarios of temperature-related mortality in Europe. Nat Commun 2011, 2:358.

82. McMichael AJ, Woodruff RE, Hales S: Climate change and human health: present and future risks. Lancet 2006, 367:859-869.

83. Adger WN, Agrawala S, Mirza MMQ, Conde C, O'Brien K, Pulhin J, Pulwarty R, Smit B, Takahashi K: Assessment of adaptation practices, options, constraints and capacity. In Clim Chang 2007 Impacts, Adapt Vulnerability Contrib Work Gr II to Fourth Assess Rep Intergov Panel Clim Chang. Edited by Parny ML, Canziani OF, Palutikof JP, van der Linden PJ, Hanson CE. Cambridge: Cambridge University Press; 2007:717-743.

84. McMichael AJ: Globalization, climate change, and human health. N Engl J Med 2013, 368:1335-1343.

85. Programme of Research on Climate Change Vulnerability Impacts and Adaptation (PROVIA): Research Priorities on Vulnerability, Impacts and Adaptation: Responding to the Climate Change Challenge. Nairobi: PROVIA 2013.

86. Cheng JJ, Berry P: Health co-benefits and risks of public health adaptation strategies to climate change: a review of current literature. Int I Public Health 2013, 58:305-311.

87. Hallegatte, S: Strategies to adapt to an uncertain climate change. Glob Environ Chang 2009, 19(2):240-247.

88. Hall JW, Brown S, Nicholls RJ, Pidgeon NF, Watson RT: Proportionate adaptation. Nat Clim Chang 2012, 2:833-834.

89. Füssel H-M: Adaptation planning for climate change: concepts, assessment approaches, and key lessons. Sustain Sci 2007, 2:265-275.

90. Wilby RL, Dessai S: Robust adaptation to climate change. Weather 2010 65:180-185.

91. Wilby RL, Vaughan K: Hallmarks of organisations that are adapting to climate change. Water Environ J 2011, 25:271-281.

92. McMichael AJ: Impediments to comprehensive research on climate change and health. Int I Environ Res Public Health 2013, 10:6096-6105

93. Bassil KL, Cole DC, Smoyer-Tomic K, Callaghan M, Team HEPHIR: What is the Evidence on Applicability and Effectiveness of Public Health Interventions in Reducing Morbidity and Mortality during Heat Episodes? Toronto: National Collaborating Centre for Environmental Health; 2007.

94. Biesbroek GR, Swart RJ, Carter TR, Cowan C, Henrichs T, Mela H, Morecroft $M D$, Rey D: Europe adapts to climate change: comparing national adaptation strategies. Glob Environ Chang 2010, 20:440-450.

95. Berrang-Ford L, Ford JD, Paterson J: Are we adapting to climate change? Glob Environ Chang 2011, 21:25-33.

96. Bobb JF, Peng RD, Bell ML, Dominici F: Heat-related mortality and adaptation to heat in the United States. Env Heal Perspect 2014, 122:811-816.

97. Coates L, Haynes K, O'Brien J, McAneney J, de Oliveira FD: Exploring 167 years of vulnerability: an examination of extreme heat events in Australia 1844-2010. Environ Sci Policy 2014, 42:33-44.

98. Petkova EP, Gasparrini A, Kinney PL: Heat and mortality in New York City since the beginning of the 20th century. Epidemiology 2014, 25:554-560.

99. Smith KR, Woodward A, Campbell-Lendrum D, Chadee D, Honda Y, Liu Q Olwoch J, Revich B, Sauerborn R, Aranda C, Berry H, Butler C, Chafe Z, Cushing L, Ebi K, Kjellstrom T, Kovats S, Lindsay G, Lipp E, McMichael T, Murray V, Sankoh O, O'Neill M, Shonkoff SB, Sutherland J, Yamamoto S: Human health: impacts, adaptation and co-benefits. In Intergov Panel Clim Chang 5th Assess Rep. Stanford: IPCC; 2014.

doi:10.1186/1471-2458-14-1112

Cite this article as: Boeckmann and Rohn: Is planned adaptation to heat reducing heat-related mortality and illness? A systematic review. BMC Public Health 2014 14:1112.

\section{Submit your next manuscript to BioMed Central and take full advantage of:}

- Convenient online submission

- Thorough peer review

- No space constraints or color figure charges

- Immediate publication on acceptance

- Inclusion in PubMed, CAS, Scopus and Google Scholar

- Research which is freely available for redistribution

Submit your manuscript at www.biomedcentral.com/submit
Biomed Central 